\title{
NAMA MARGA SEBAGAI IDENTITAS BUDAYA MASYARAKAT ETNIS ARAB
}

\author{
Dita Kafaabillah \\ Program Pascasarjana UIN Sunan Kalijaga \\ Email: dita.elkafa@gmail.com
}

\begin{abstract}
Abstrak
Relativitas budaya dan bahasa memiliki hubungan yang berkesinambungan. Marga merupakan hasil dari proses kebudayaan secara turun-temurun. Suatu marga dapat menyimpan harapan, doa, cita-cita leluhur, peristiwa, dan sejarah kehidupan seseorang Artikel ini menjelaskan konsep penamaan dan pemaknaan marga masyarakat etnis Arab yang berupaya mengungkap proses pelambangan suatu marga yang mengacu kepada suatu referen dan konsep makna yang terefleksikan di dalamnya. Data penelitian ini dijaring dengan metode simak dan cakap. Adapun analisisnya memanfaatkan metode padan referensial dengan teknik dasar Pilah Unsur Penentu (PUP)dan teknik lanjutan Hubung Banding Menyamakan (HBS). Pada nama marga masyarakat etnis Arab tercermin corak budaya yang kuat dalam sistem kekerabatan sebagai identitas yang dilestarikan turun-temurun.
\end{abstract}

Kata kunci: antropolinguistik, masyarakat etnis Arab, marga, identitas

\section{CLAN NAMES AS A CULTURAL IDENTITY OF THE ARAB COMMUNITY}

\begin{abstract}
Cultural relativity and language have a continuous relationship. Marga is the result of hereditary cultural processes. A clan can store one's hopes, prayers, ancestral ideals, events, and life history. This article explains the concept of naming and interpreting Arab ethnic community clans and attempts to reveal the process of symbolizing a clan that refers to a referent and semantic concept reflected in it. The data were collected through observations and interviews. The analysis used the referential correspondence method with the basic technique of the Immediate Constituent Analysis (ICA) the advanced technique of Equal Comparative Relation (ECR). In the Arabethnic community, a clan name reflects a strong cultural pattern in the kinship system as an identity that has been preserved from generation to generation.
\end{abstract}

Keywords: anthropolinguistics, Arabethnic community, clan, identity

\section{PENDAHULUAN}

Bangsa Indonesia dengan kemajemukan penduduknya bertebaran berbagai etnis dan budaya, salah satunya adalah etnis Arab. Mereka mayoritas berasal dari negeri Hadhramaut, Yaman. Kedatangan mereka ke Indonesia terbagi menjadi empat gelombang. 
Gelombang pertama diawali abad ke$12 \mathrm{M}$, yaitu sejak kedatangan Ulama Ba'lawi dari marga Shihab. Gelombang kedua terjadi pada awal abad ke-18 yang terdiri dari marga Assegaf, al-Habsyi, al-Hadad, al-Aydrus, al-Atas, al-Jufri, Syihab, Shahab, Jamalulail, al-Qadri, Basyaiban dan bin Yahya. Setelah itu disusul gelombang ketiga di awal abad ke-19 yang mayoritas adalah dari golongan non-Habaib atau yang disebut dengan Ghabili. Selanjutnya, gelombang keempat terjadi di awal abad ke-20 M yang dilatarbelakangi adanya polemik di negara Yaman. Pada hakikatnya, gelombang pertama dan kedua mayoritas adalah golongan Habib dan Sayid yang misi utamanya lebih berkiprah dalam dunia dakwah agama Islam. Hal ini berbeda dengan mereka yang datang pada gelombang ketiga dan keempat yang membawa misi sosial, ekonomi di samping misi agama (Bahafdullah, 2000:167-171).

Masyarakat etnis Arab di Indonesia menyebar ke seluruh penjuru Nusantara. Mereka hidup berdampingan dengan masyarakat pribumi. Pada umumnya mereka tinggal berkelompok di perkampungan-perkampungan Arab yang tersebar diberbagai wilayah di Indonesia. Adapun salah satu wilayah yang banyak terdapat etnis Arab di Nusantara adalah Surakarta.

Kota Surakarta merupakan pusat wilayah eks-Karesidenan Surakarta, secara sosio-kultural Kota Surakarta merupakan pusat pertemuan antara penduduk asli dengan para pendatang yang heterogen dari berbagai daerah, salah satunya adalah etnis Arab. Di Surakarta mayoritas etnis Arab hidup di Kecamatan Pasar Kliwon. Kecamatan ini merupakan sentral kegiatan masyarakat Arab, sehingga daerah ini sering disebut juga dengan kampung Arab.

Masyarakat etnis Arab menunjukkan eksistensinya dalam berbagai bidang, seperti: keagamaan, ekonomi, politik, bahasa, maupun budaya. Hal ini dapat ditandai dengan maraknya masjid-masjid, toko-toko, tokoh-tokoh politisi serta sejumlah tradisi khas yang dimiliki oleh mereka. Salah satu tradisi yang menarik dari etnis ini adalah penggunaan marga pada nama mereka. Nama marga merupakan aspek yang sangat sentral dalam kehidupan masyarakat etnis Arab. Nama marga merupakan tradisi turun-temurun yang dijaga keberlanjutannya sebagai identitas diri etnis Arab.

Nama merupakan penanda identitas yang tak terpisahkan pada diri seseorang. Widodo (2012:1) mengungkapkan bahwasanya nama adalah sesuatu yang selalu disebut dan dipahami sebagai kata, istilah, atau ungkapan yang digunakan untuk mengenali seseorang atau sesuatu dari yang lainnya. Dengan demikian, nama memegang peranan sentral dalam kehidupan manusia.

Dalam komunikasi sehari-hari, nama marga merupakan istilah rujukan untuk mengetahui identitas kekerabatan seseorang. Menurut Sibarani (2004:109) marga "nama keluarga/ kerabat" adalah nama yang diberikan kepada seseorang dengan otomatis berdasarkan kekerabatan yang unilinear atau garis keturunan geneologis secara patrilineal dari satu nenek moyang. Oleh karena itu, melalui marga dapat diketahui asal-usul kekerabatan pada diri seseorang.

Nama marga ini diletakkan dibelakang nama diri seseorang. Penamaan 
marga muncul tidak serta merta begitu saja, namun melalui berbagai proses sosial-kultural. Proses penamaan marga dilatarbelakangi dari berbagai aspek. Aspek penamaan marga dapat dilatarbelakangi antara lain untuk menjaga garis keturunannya agar tidak luntur akibat perkawinan di luar etnis Arab. Melalui marga pula etnis Arab diharapkan dapat mengingat nilai-nilai leluhur nenek moyang mereka. Selain itu dengan adanya marga, secara praktis mereka dapat saling mengenal dan mengetahui sistem kekerabatan pada diri seseorang.

Konsep pemargaan menjadi salah satu indikator pengungkap karakteristik budaya masyarakat etnis Arab. Tradisi pemargaan ini dapat merefleksikan kondisi psikologis masyarakat etnis Arab secara global, yang kemudian dapat dilihat struktur berpikir dari masyarakatnya. Pola pikir ini pada akhirnya turut merefleksikan struktur sosial budaya masyarakat etnis Arab pada tataran yang lebih praktis. Di samping itu, praktek pemargaan juga menjadi salah satu indikator idiologis suatu kelompok masyarkat yang mencakup nilai-nilai yang dianut (baik-buruk, pantas-tidak pantas), serta keyakinan, dan harapan bahwa nama yang diberikan tersebut akan sesuai dengan yang dicita-citakan kelak.

Marga menyimpan berbagai refleksi kehidupan yang terdapat di dalamnya. Melalui marga tersimpan cerita, peristiwa, kejadian, keadaan, kenangan, dan harapan dari para leluhur kepada si pemilik marga. Dengan demikian, fenomena pemargaan secara implisit dapat mengungkapkan pikiran, perasaan, dan perilaku dari suatu bangsa atau kelompok masyarakat yang tercermin dari suatu marga.
Relativitas pemargaan etnis Arab dipengaruhi oleh corak kebudayaan asli masyarakatnya. Sapir Whorf (dalam Wijana dan Rohmadi, 2006:8) menggambarkan bahwa antara relativitas budaya dan bahasa memiliki hubungan timbal balik. Pola hubungan antara masyarakat, budaya, dan bahasa tidak dapat terpisahkan kaitannya. Seseorang tidak dapat memahami bahasa tanpa mengetahui budayanya. Sebaliknya pula, budaya masyarakat tidak dapat dipahami tanpa melalui kajian kebahasaan, karena suatu bahasa dihasilkan oleh budayanya, dan budaya masyarakat dapat tercermin melalui bahasanya.

Melalui kajian marga secara komprehensif dapat mengungkap nilai-nilai kebudayaan yang terkandung dalam marga. Sibarani (2004:108) mengungkapkan bahwa nama adalah penanda identitas yang dapat meperlihatkan budaya. Untuk mengkaji persoalan yang ada, diperlukan kajian antropolinguistik yang memadukan antara kajian kebahasaan dengan kebudayaan. Antropolinguistik adalah gabungan antara dua disiplin ilmu yaitu antropologi dan linguistik.

Sibarani (2004:50) mendefinisikan antropolinguistik sebagai cabang ilmu yang mempelajari variasi dan penggunaan bahasa dalam hubungannya dengan perkembangan waktu, perbedaan tempat komunikasi, sistem kekerabatan, pengaruh kebiasaan etnik, kepercayaan, etika bahasa, adat istiadat, dan pola-pola kebudayaan lain dari suatu suku bangsa. Adapun menurut Ratna (2011:295) antropologi adalah ilmu tentang manusia, sedangkan linguistik adalah ilmu mengenai bahasa. Dalam kaitan ini Greertz (dalam Bawa, 
2004:21-21) mengemukakan bahwa antropolinguistik adalah penafsiran dan pencarian makna dalam kehidupan masyarakat, termasuk bahasa (langue) dan tuturan (speaking) yang merupakan sistem simbol (bunyi dan tulisan). Penafsiran makna-makna yang dinamis ini diwadahi oleh banggunan kebahasaan yang konvensional sehingga dapat dipahami manusia melaui polapola kebahasaan yang terdapat dalam kehidupan masyarakat. Oleh karena itu, ruang lingkup antropolinguistik tidak hanya mengkaji variasi bahasa dalam masyarakat melainkan makna bahasa yang terdapat dalam kehidupan.

Penelitian ini juga berpijak pada teori Chaer (2013) untuk menganalisis konsep penamaan masyarakat etnis Arab. Chaer (2013:44-52) membagi latar belakang penamaan menjadi sembilan poin, adapun teori penamaan tersebut adalah sebagai berikut: (1) Peniruan Bunyi, (2) Penyebutan Bagian, (3) Penyebutan Sifat Khas, (4) Penemu atau Pembuat, (5) Tempat Asal, (6) Bahan, (7) Keserupaan, (8) Pemendekan, (9) Penamaan Baru. Dengan pendekatan ini, penamaan marga Arab dapat ditelusuri sebab-sebab dan peristiwa-peristiwa yang melatarbelakangi penamaan suatu marga sehingga akan tampak referen dari penamaan marga yang ada. Adapun dari segi pemaknaan kaitannya dengan budaya, penulis berpijak pada teori Sibarani (2004) untuk menganalisis konsep pemaknaan nama marga etnis Arab. Sibarani (2004) membagi tiga makna nama dalam antropolinguistik yaitu: makna futuratif, situasional dan kenangan.

Dengan kajian tersebut, penelitian ini bertujuan untuk mengungkap dan menjelaskan fenomena-fenomena ke- bahasaan yang terdapat dalam namanama marga etnis Arab. Fenomenafenomena pemargaan initidak bisalepas dari hal-hal yang melatarbelakanginya. Dengan mengetahui latar belakang penamaan marga dapat diketahui referen dari marga masyarakat etnis Arab dan faktor-faktor di balik kemunculannya. Selain itu penelitian ini bertujuan untuk mengungakap makna-makna yang tersimpan dalam marga masyarakat etnis Arab. Marga-marga ini ditafsirkan secara kebahasaan de-ngan pendekatan antropologis, sehingga akan mucul makna-makna di balik suatu marga. Melalui kajian penamaan dan pemaknaan, secara mikro dapat diketahui struktur pemikiran masyarakat etnis Arab dan secara makro dapat tercermin corak kebudayaan masyakaratnya.

\section{METODE}

Penelitian ini berupaya mendiskripsikan konsep penamaan dan pemaknaan marga masyarakat etnis Arab. Populasi penelitian ini adalah keseluruhan nama-nama marga yang disandang oleh masyarakat etnis Arab di wilayah Kota Surakarta. Adapun sampel dalam penelitian ini diperoleh dengan teknik purposive sampling. Penelitian ini mengambil sampelnya di Kelurahan Pasar Kliwon yang dikenal sebagai sentral kampung Arab di Kota Surakarta. Penelitian ini relevan dengan penelitian yang dilakukan oleh Sahayu (2014:338-348) yang berjudul "Penanda Jenis Kelamin pada Nama Jawa dan Jerman", dalam Litera Volume 16 (2). Bedanya objek penelitian yang oleh Sahayu berkaitan dengan penanda jenis kelamin dari nama Jawa dan Jerman, sedangkan penelitian ini mengkaji nama-nama marga yang ditinjau dari segi penamaan dan pemak- 
naanya. Selain itu, penelitian ini mengambil sampel masyarakat etnis Arab dari golongan Alawiyyin yang secara stratifikasi sosial merupakan golongan dengan tingkat sosial tertinggi di masyarakat etnis Arab.

Penelitian ini melewati tiga tahapan strategis yang diwujudkan dalam bentuk metode untuk memecahkan masalah yang ada. Tahapan-tahapan tersebut yaitu (1) metode penyediaan data; (2) metode analisis data; (3) metode penyajian hasil analisis (Sudaryanto, 1993).

Penelitian ini dalam penyediaan datanya memanfaatkan metode simak dan metode cakap. Metode simak dalam penelitian ini menggunakan teknik sadap dengan teknik lanjutan simak bebas libat cakap. Adapun data yang disadap berkaitan dengan data penduduk Kelurahan Pasar Kliwon Surakarta. Data tersebut dijaring melalui pengambilan data yang termasuk marga etnis Arab dan diklasifikasikan menurut kelompok marganya. Selain itu, penelitian ini juga memanfaatkan metode cakap dengan teknik pancing, teknik cakap semuka (CS), teknik rekam, dan teknik catat. Metode cakap ini berbentuk wawancara terhadap lima informan tokoh masyarakat etnis Arab (selanjutnya dapat disingkat MEA). Metode cakap ini dimanfaatkan guna menemukan informasi langsung dari pemilik marga mengenai pola kebiasaan MEA dan seluk-beluk marganya. Setelah data tersebut didapatkan, maka tahap selanjutnya adalah pengklasifikasian data. Data diklasifikasikan melalui pendekatan konsep penamaan dan pemaknaan. Dalam aspek penamaan, penelitian ini mencari informasi-informasi mengenai referen dan latar belakang penamaan marga MEA. Adapun dalam aspek pe- maknaan, penelitian ini menggali informasi mengenai makna-makna yang terkandung dalam nama marga MEA baik dari segi bahasa maupun budaya yang memengaruhinya.

Setelah tahap penyediaan data dilaksanakan, tahap selanjutnya adalah analisis data. Penganalisisan data penelitian ini memanfaatkan metode padan referensial guna menemukan konsep penamaan dan pemaknaanya. Metode padan referensial adalah metode yang alat penentunya berupa kenyataan yang ditunjuk oleh bahasa atau referen bahasa (Sudaryanto, 1993: 13). Adapun teknik yang dibutuhkan adalah teknik dasar Pilah Unsur Penentu (PUP) dengan teknik lanjutan berupa teknik Hubung Banding Menyamakan (HBS).

Teknik PUP dimanfaatkan guna menganalisis marga berdasarkan konsep pemargaannya. Konsep pemargaan ini dibagi menjadi dua sudut pandang, yaitu: penamaan dan pemaknaan. Dalam aspek penamaan, nama marga dianalisis berdasarkan referen dan latar belakang kemunculan suatu marga. Adapun dalam aspek pemaknaan, marga MEA ditafsirkan maknanya dengan mengkombinasikan data wawancara dengan literatur yang ada. Jadi, dari segi penamaan dan pemaknaan, penentuan referennya berdasarkan sejarah yang melatarbelakangi penamaan marga dan konsep makna yang tersingkap di balik marga

Setelah dianalisis melalui teknik PUP, maka data yang ada dianalisis melalui teknik lanjutan HBS. Menurut Kesuma (2007: 53) teknik HBS adalah teknik analisis data yang alat penentunya berupa daya banding menyamakan di antara satuan-satuan kebahasaan yang ditentukan identitasnya. Penentu- 
an identitas dalam penelitian ini menghasilkan beberapa pembagian marga yang dikelompokkan berdasarkan jenis penamaan dan pemaknaannya.

Pada tahap penyajian hasil analisis, data disajikan dalam bentuk laporan penelitian dengan menggunakan metode formal dan informal. Secara formal, hasil penelitian ini disajikan dalam bentuk diagram. Adapun secara informal, penyajian hasil analisis penelitian ini menggunakan kata-kata biasa walaupun dengan terminologi yang teknis sifatnya (Sudaryanto, 1993).

\section{HASIL DAN PEMBAHASAN Konsep Pemargaan Etnis Arab}

Masyarakat etnis Arab mencantumkan marganya di akhir namanya. Nama marga ini diperoleh dari garis keturunan ayah (patrilineal) yang selanjutnya diteruskan kepada keturunannya secara turun-temurun. Nama marga merupakan suatu rujukan yang penting dikalangan MEA untuk menentukan asal-usul garis keluarga. Nama marga dikalangan MEA merupakan suatu penanda identitas yang tidak dapat dipisahkan. Hal ini disebabkan karena budaya masyarakat Arab sangat menjunjung konsep nasab.

Pemargaan merupakan suatu bentuk identitas yang dipertahankan dan dipegang teguh oleh masyarakat etnis Arab. Mereka berkeyakinan bahwa masyarakat etnis Arab adalah keturunan yang terhormat, sehingga tak heran jika mereka sangat menjaga sistem pemargaan yang ada. Konsep pemargaan etnis Arab ini ditentukan melalui jalur pernikahan di antara mereka.

Bentuk pernikahan yang berlaku pada mayoritas masyarakat Arab ada- lah endogami. Aturan yang ditetapkan mereka berdasarkan prinsip patrilineal yang apabila seorang perempuan etnis Arab menikah dengan non-Arab maka garis keturunannya akan terputus. Adapun bagi laki-laki etnis Arab, penarikan garis keturunannya tetap dari pihak mereka, sehingga tidak masalah jika mereka menikah dengan etnis nonArab. Hal ini berdampak pada sistem sosio-kultural di antara keturunan Arab dan pribumi yang pada akhirnya berimplikasi pada penamaan marga.

\section{Konsep Penamaan Marga Etnis Arab}

Nama-nama marga MEA terbagi menjadi dua golongan besar, yaitu: Arab Aribah dan Arab Musta'ribah. Arab Aribah adalah mereka yang mengaku dirinya sebgai orang Arab asli karena mereka merupakan pengguna bahasa Arab pertama. Adapun Arab Musta'ribah yang secara bahasa diartikan 'yang diarabkan atau yang dianggap Arab. Arab Musta'ribah ini berasal dari keturunan Nabi Muhammad SAW atau yang biasa disebut golongan Alawiyyin. Nama-nama marga yang ditemukan dalam penelitian ini yaitu: Adni, Aidid, al-Atas, al-Aydrus, al-Habsyi, al-Hadad, al-Hamid, al-Jufri, al-Junaid, al-Kaff, al-Masyhur, Assegaf, Ba'agil, Basri, Sahl, bin Tahir, Yahya, Mulachela, Musawa, Syahab, dan Syatri. Setelah dilakukan analisis data, ditemukan lima jenis konsep penamaan marga. Lima jenis konsep penamaan tersebut yaitu, marga yang referennya merujuk kepada nama tokoh, tempat, sifat, peristiwa, dan kebiasaan. Berikut ini adalah prasentase acuan penamaan marga MEA Surakarta. 


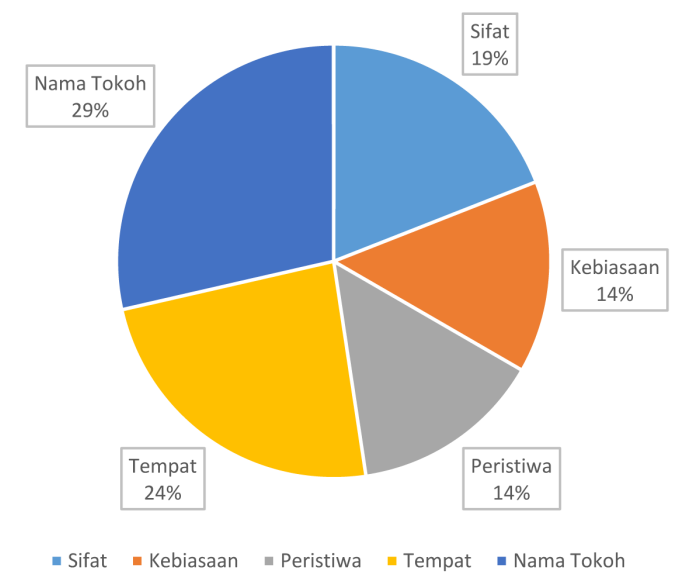

Gambar 1. Prosentase Referen Penamaan Marga MEA

Sebagaimana tampak pada gambar 1, penamaan marga MEA didominasi berdasarkan latar belakang nama tokoh. Dari dua puluh satu kelompok nama marga, ditemukan enam marga MEA (atau sebesar 29\%) mengacu pada konsep penamaan nama tokoh. Adapun diurutan kedua, didominasi dengan konsep penamaan marga berdasarkan tempat sejumlah lima marga (atau sebesar 24\%). Diurutan selanjutnya yaitu nama marga mengacu kepada sifat sejumlah empat marga (atau sebesar 19\%). Adapun sisanya, mengacu pada latar belakang peristiwa sejumlah tiga marga (atau sebesar 14\%), dan berdasarkan kebiasaan sejumlah tiga marga juga (atau sebesar 14\%).

Secara umum nama marga mengacu pada penamaan marga berdasarkan nama tokoh. Penamaan marga berdasarkan nama tokoh adalah penamaan yang referennya kembali pada nama seseorang yang dijadikan idola dan panutannya. Penamaan seperti ini terdapat pada marga: al-Junaid, Ba'agil, Sahl, bin Tahir, Yahya, dan Musawa. Misalnya marga Musawa, Marga ini pertama kali disandang oleh waliullah Ahmad bin Muhammad bin Ahmad bin Abu Bakar as-Sakran bin Abdurrahman Assegaf (Aidid, 1999: 68). Penamaan marga ini mengacu kepada nama seorang tokoh gurunya di Yaman yang bernama Musawa (alMasyhur, 2013: 249). Ditinjau dari segi latar belakang penamaannya, kemunculan marga Musawa didasari karena adanya hasrat agar anak keturunannya dapat mencontoh sikap dan ketinggian ilmu dari gurunya. Dari situlah dapat ditarik kesimpulan bahwasanya marga Musawa tergolong penamaan marga berdasarkan nama tokoh.

Di samping penggunaan nama marga yang mengacu pada nama tokoh, marga MEA juga mengacu pada penamaan berdasarkan tempat asal. Penamaan berdasarkan referen tempat asal adalah nama marga yang diambil berdasarkan nama suatu daerah. Penamaan seperti ini dapat ditemukan pada marga: Adni, Aidid, al-Habsyi, Basri dan Mulachela. Misalnya marga alHabsyi, Marga ini pertama kali disandang oleh waliullah Abi Bakar bin Ali bin Ahmad bin Muhammad Asadillah bin Hasan Atturabi bin Ali bin $\mathrm{Mu}-$ hammad al-Faqih Muqaddam bin Ali bin Muhammd Shahib Marbad (Aidid, 1999: 57). Latar belakang penamaan marga ini dikarenakan waliullah Abi Bakar bin Ali pernah tinggal selama 20 tahun di Kota Habasyah, Afrika (Aidid, 1999: 57). Wilayah Habasyah pada zaman sekarang dikenal dengan negara Ethiopia. Penamaan marga al-Habsyi disandarkan pada nama suatu tempat yang pernah ditinggali seseorang ini menjadikannya tergolong dalam penamaan marga berdasarkan tempat.

Selain nama marga yang mengacu pada nama tokoh dan tempat, ada pula 
yang mengacu pada sifat. Penyebutan sifat adalah penamaan suatu marga berdasarkan sifat yang menonjol pada diri seseorang. Penamaan suatu marga yang dilatarbelakangi berdasarkan penyebutan sifat terdapat pada marga: al-Hamid, al-Jufri, al-Masyhur dan Syahab. Contohnya marga al-Jufri, marga ini pertama kali disandang oleh waliullah Abu Bakar bin Muhammad bin Ali bin Muhammad bin Ahmad bin Muhammad al-Faqih Muqaddam (al-Masyhur, 2013: 205). Dimasa kecilnya, waliullah Abu Bakar bin Muhammad mempunyai badan yang besar dan kekar. Bentuk fisik beliaulah yang memicu datuknya yaitu waliullah Abdurrahman Assegaf bin Muhammad Mauladdawilah menjulukinya dengan al-Jufri. Ketika itu, datuknya menyapa beliau dengan sapaan 'Ahlan Jufratiy' yang berarti 'hai anak kecil yang berbadan gemuk dan kekar' (Aidid, 1999: 50). Sifat gemuk dari karakteristik fisik dari seseorang ini menjadi fokor utama munculnya marga al-Jufri. Dari aspek kebahasaan, kata gendut dan kekar merupakan bentuk kata sifat. Penamaan marga yang mengacu pada sifat yang menonjol dari pemiliknya ini menjadi titik tolak penklasifikasian marga ini ke dalam penamaan berdasarkan sifat.

Dari penelitian ini juga ditemukan penamaan marga yang mengacu pada kebiasaan. Penamaan berdasarkan kebiasaan adalah suatu penamaan terhadap seseorang yang dilatarbelakangi karena hal-hal yang biasa dikerjakannya secara berulang-ulang. Penamaan seperti ini dapat dijumpai pada marga al-Hadad, Assegaf, dan Syatri. Misalnya marga Assegaf, marga ini pertama kali disandang oleh waliullah Abdurrahman bin Muhammad Mauladdawilah bin Ali bin Alwi bin Muhammad alFaqih al-Muqaddam (Aidid, 1999: 73). Penamaan marga Assegaf dilatarbelakangi oleh kebiasaan beliau yang dikenal sebagai pengayom para wali pada zamannya. Beliau diibaratkan sebagai atap bangunan yang dalam bahasa Arab disebut saqfun. Kebiasaan yang suka mengayomi ini menjadikan marga Assegaf tergolong dalam konsep penamaan marga berdasarkan kebiasaan.

Selain itu, ditemukan pula penamaan marga yang referenya mengacu pada suatu peristiwa. Penamaan berdasarkan peristiwa adalah penamaan terhadap seseorang yang dilatarbelakangi karena suatu kejadian yang dialaminya. Penamaan seperti ini ditemukan pada marga al-Atas, al-Aydrus, dan al-Kaff. Marga al-Aydrus misalnya, marga ini pertama kali disandang oleh waliullah Abdullah bin Abi Bakar Assakran bin Abdurrahman Assegaf (Aidid, 1999: 39). Marga al-Aydrus adalah marga pemberian dari datuknya yang bernama waliullah Abdurrahman Assegaf kepada waliullah Abdullah bin Abi Bakar. Secara kebahasaan, al-Aydrus mempunyai arti 'macan/singa'. Adapun latar belakang pemberian marga ini dikarenakan dimasa kecilnya dia berani menghadapi apaun juga (baik manusia, makhluk-makhluk halus dan sebagainya) (Aidid, 1999: 39). Kejadian tersebutlah yang menyebabkan dia diberi gelar al-Aydrus yang kemudian menjadi nama marganya.

\section{Konsep Pemaknaan Nama Marga Et- nis Arab}

Kaitannya dengan hal pemaknaan, nama marga MEA memiliki makna dan maksud yang bervariasi. Makna dan maksud yang terdapat dalam nama 
marga dapat menyimpan doa, pengharapan, kisah, peristiwa, ataupun sejarah kehidupan. Paling tidak, ditemukan tiga jenis makna marga berdasarkan pembagian dari Sibarani (2004), yaitu: makna futuratif, situasional, dan kenangan. Berikut ini adalah gambar persentase konsep pemaknaan marga MEA.

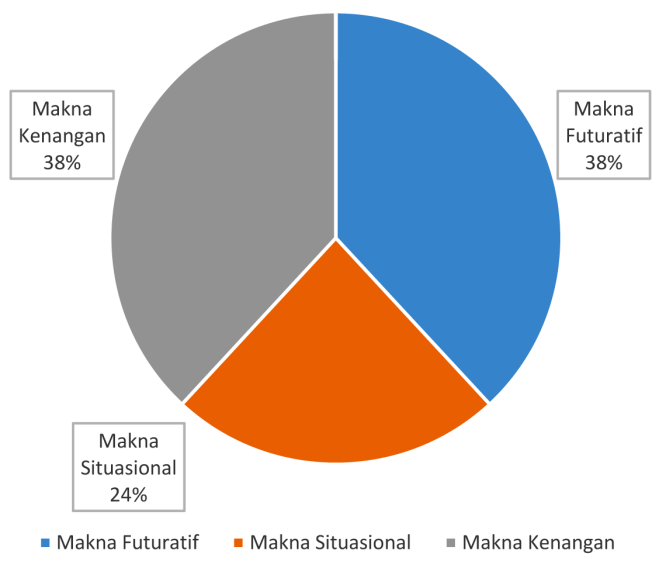

\section{Gambar 2. Persentase Konsep Pemaknaan Marga MEA}

Dari gambar 2 di atas, dapat diketahui bahwasannya marga MEA didominasi dengan konsep pemaknaan futuratif dan kenangan. Baru diikuti kemudian dengan konsep pemaknaan situasional. Dari dua puluh satu nama marga MEA, ditemukan delapan marga (atau sebesar 38\%) yang terklasifikasi dalam pemaknaan futuratif dan delapan marga pula (atau sebesar 38\%) yang terklasifikasi dalam pemaknaan kenangan. Adapun persentase terkecil yaitu sejumlah lima marga (atau sebesar 24\%) terklasifikasikan dalam konsep pemaknaan situasional.

Suatu marga yang mengandung makna futuratif adalah penamaan yang menyimpan pengharapan terhadap seseorang agar kehidupan pemiliknya se- suai ekspektasi yang diharapkan (Sibarani, 2004). Marga yang menyingkap makna futuratif di antaranya yaitu marga: al-Hamid, al-Junaid, Ba'agil, Sahl, Musawa, Syahab, Yahya, dan bin Thahir. Marga Yahya misalnya, ditinjau dari segi pemaknaan, kata Yahya dalam Mu'jamu'l-Lughatul 'Arabiyyatu'lMu'ashirah karya Umar (2008: 2509) dimaknai dengan 'salah satu Nabi dari Bani Israil'. Marga Yahya mengandung suatu pengharapan kepada si pemilik agar orang-orang yang menyandang marga tersebut dapat mencontoh kepribadian dari Nabi Yahya 'alaihi'ssalam dan mendapat keberkahan darinya (Aidid, 1999: 82). Menurut Umar bin Husain Assegaf, (salah seorang tokoh MEA di Pasar Kliwon Surakarta) "marga Yahya diambil dari nama sesepuh mereka yang tersohor dimasanya dengan keilmuannya dan keshalihannya". Adanya suatu harapan agar pemiliknya dapat mencontoh dan mendapat berkah dari nabi Yahya 'alaihi's-salam menjadikan marga ini tergolong dalam konsep pemaknaan futuratif.

Selain pemaknaan marga yang futuratif, ditemukan pula marga yang menyimpan makna situasional. Makna situasional adalah makna nama yang mengandung informasi mengenai kondisi kehidupan dari pemilik nama marga. Makna seperti ini dapat ditemui pada marga Adni, Aidid, al-Habsyi, Basri, dan Mulachela. Misalnya marga Mulachela, secara kebahasaan marga Mulachela (Maulakhala) yang dapat diartikan 'tuan pegunungan Khailah. Menurut Umar bin Husain Assegaf (salah seorang tokoh MEA di Pasar Kliwon Surakarta) marga Mulachela yang menggunakan awalan maula berarti 'tuan', dan khala merupakan nama 
suatu daerah di Tarim yang dahulunya tempat tersebut jarang dihuni oleh orang, sehingga tempat tersebut dinamai Khala yang artinya kosong atau sepi' (wawancara, 21 Juni 2015 jam 22.30 WIB). Hal ini memberikan suatu informasi mengenai kondisi tempat tinggal yang sepi pendahulunya, kemudian didiami seorang tokoh berkuasa di daerah tersebut dan dijulukilah dia $\mathrm{Mu}-$ lachela. Dari pembahasan di atas, tampak bahwa marga Mulachela menyimpan suatu informasi geografis di daerah pegunungan Chailah Hadramaut yang dulu kondisinya sepi, sehingga marga ini menyimpan makna situsional yaitu daerah yang sepi.

Ditemukan pula nama marga yang menyimpan makna kenangan. Makna kenangan adalah makna marga yang mengandung cerita di masa lampau. Makna ini terdapat pada marga: al-Hadad, al-Atas, al-Aydrus, al-Jufri al-Kaff, al-Masyhur, Assegaf, dan Syatri. Misalnya marga al-Hadad, marga ini menyimpan suatu kisah kehidupan waliullah Ahmad bin Abi Bakar sebagai penyandang pertama marga ini. Adapun kisah kehidupannya adalah suka bergaul dengan Pandai Besi dan suka berdakwah (Aidid, 1999: 58). Menurut Umar bin Husain Assegaf (tokoh MEA Pasar Kliwon Surakarta) marga al-Hadad dalam bahasa Arab artinya 'pandai besi', dalam konteks ini bukan menunjukkan suatu profesi sebagai pandai besi itu sendiri, akan tetapi maksudnya pandai adalah mudah menghilangkan hal-hal yang mengotori hati dan yang tersisa adalah hal-hal yang baik, sehingga ucapannya dapat membersihkan hati (wawancara 21 Juni 2015). Kisah masa lampau di balik penamaan marga al-Hadad ini. Menjadikan marga
al-Hadad termasuk dalam marga yang bermakna kenangan.

\section{SIMPULAN}

Berdasarkan perbincangan mengenai marga sebagai identitas MEA, menujukkan adanya keberagaman tradisi budaya yang terbalut di dalam sejarah budaya yang sangat panjang. Pada perkembangannya, marga tidak lagi menjadi identitas bagi penyandangnya, namun menjadi perwujudan sikap hidup dan selera budaya masyarakat yang senantiasa dijaga seiring perkembangan zaman. Selain itu, pemahaman berkaitan dengan konsep penamaan dan pemaknaan marga ini menunjukkan adanya sistem penamaan marga MEA yang sistemik yang didokumentasikan dalam nama marga.

Tiap nama marga memiliki konsep penamaan dan pemaknaan yang unik dan bervariasi. Dari penelitian yang telah dilaksanakan, dapat dirumuskan bahwa referen penamaan marga MEA terbagi menjadi ke dalam lima jenis konsep penamaan yaitu, mengacu pada referen nama tokoh, tempat, sifat, kebiasaan, dan peristiwa. Adapun konsep pemaknaannya terdiri dari tiga kategori, yaitu: makna futuratif, situasional, dan kenangan.

Nama marga tidak hanya sekedar nama yang diturunkan dari generasi ke generasi melainkan nama marga menyimpan berbagai peristiwa, harapan, doa, kondisi, kenangan, kebiasaan dan sejarah hidup seseorang. Latar belakang penamaan dan pemaknaan ini mencerminkan keyakinan, selera budaya, ideologis dan struktur berfikir dari MEA. Di samping itu nama marga adalah penanda identitas yang menyimpan makna-makna masa lalu yang dapat 
ditelusuri, dipelajari, dikenang dan diupayakan eksistensinya agar tidak luntur seiring perkembangan zaman.

\section{UCAPAN TERIMA KASIH}

Peneliti mengucapkan terima kasih yang tulus kepada mitra bestari yang telah memberikan masukan untuk perbaikan artikel ilmiah ini. Peneliti juga mengucapkan terima kasih kepada Muhammad Ridwan, S.S., M.A. (Dosen Program Studi Sastra Arab, FIB, Universitas Sebelas Maret Surakarta) yang telah mengarahkan peneliti sehingga dapat menyelesaikan penelitian ini. Selain itu, terima kasih pula kepada Ditjen Dikti dan para reviewer yang telah menfasilitasi dan mendanai dalam penelitian ini.

\section{DAFTAR PUSTAKA}

Aidid, Muhammad Hasan. 1999. Petunjuk Monogram Silsilah Berikut Biografi dan Arti Gelar Masing-masing Leluhur Alawiyyin. Jakarta: Amal Shaleh.

Al-Masyhur, Idrus Alwi. 2013. Sejarah, Silsilah \& Gelar Keturunan Nabi Muhammad SAW di Indonesia, Singapura, Malaysia, Timur Tengah, India, dan Afrika. Jakarta: Saraz Publishing.

Bahafdhullah, A. Majid Hasan. 2010. Dari Nabi Nuh A.S. Sampai Orang Hadramaut di Indonesia: Menelusuri Asal Usul Hadharim. Jakarta: Bania Publishing.

Bawa dan I Wayan Cika (penyunting). 2004. Bahasa dalam Perspektif Kebudayaan. Denpasar: Universitas Udayana.
Chaer, Abdul. 2013. Pengantar Semantik Bahasa Indonesia. Jakarta: PT. Rineka Cipta.

Kesuma, Tri Mastoyo Jati. 2007. Pengantar (Metode) Penelitian Bahasa. Yogyakarta: Carasvatibooks.

Ratna, Nyoman Kutha. 2001. Antropologi Sastra: Peran Unsur-unsur Kebudayaan dalam Proses Kreatif. Yogyakarta: Pustaka Pelajar.

Sibarani, Robert. 2004. Antropologi Linguistik: Antropologi Linguistik, Linguistik Antropologi. Medan: Penerbit Poda.

Sudaryanto. 1993. Metode dan Aneka Teknik Analisis Bahasa. Yogyakarta: Duta Wacana University Press.

Umar Achmad Mukhtar. 2008. Mu'jamul-Lughatul-ArabiyyatulMu'ashirah Majallidil- Awwal. Kairo: 'Alamul-Kutub.

Widodo, Sahid Teguh dkk. 2012. Nama Orang Jawa (Dinamika Perkembangan Bentuk dan Makna). Surakarta: Program Buku Teks Sebelas Lembaga Pusat Pengembangan - Universitas Sebelas Maret.

Wijana, I Dewa Putu dan Muhammad Rohmadi. 2006. Sosiolinguistik. Yogyakarta: Pustaka Pelajar.

Sahayu, Wening. 2014. "Penanda Jenis Kelamin pada Nama Jawa dan Nama Jerman." dalam Litera Volume 13 Nomor 2: 338-348

\section{Wawancara}

Wawancara dengan Umar bin Husain Assegaf, informan asal Dusun Semanggi Kelurahan Pasar Kliwon Kec. Pasar Kliwon, Kota Surakarta. 